\title{
Essential Oil Composition and Antioxidant Activity of Calamintha officinalis Moench
}

\author{
Fatemeh Shams Moattar ${ }^{1}$, Reyhaneh Sariri ${ }^{*}$, Masoud Giahi ${ }^{3}$, Prichehreh Yaghmaee ${ }^{1}$ \\ ${ }^{1}$ Department of Biology, Science and Research Branch, Islamic Azad University, Tehran, Iran \\ ${ }^{2}$ Deparment of Biology, University of Guilan, Rasht, Iran \\ ${ }^{3}$ Department of Biology, Islamic Azad University, Lahijan Branch, Lahijan, Iran
}

Corresponding Author: Reyhaneh Sariri, Professor, Deparment of Biology, University of Guilan, Rasht, Iran.

Email: sariri@guilan.ac.ir

Received September 15, 2017; Revised December 7, 2017; Accepted February 17, 2018; Online Published June 20, 2018

\begin{abstract}
Introduction: Calamintha officinalis Moench (COM) is an aromatic herb from Lamiaceae family with high similarities to the common mints not only in its appearance but also in terms of aroma. The aim of this research was to evaluate antioxidant activity of plant extract and to identify constituents of its essential oil.

Material and Methods: The plant samples were collected from North of Iran (Guilan, Lahijan) and its identity was certified by a systematic botanist in University of Guilan. The dried leaves of COM were subjected to hydro-distillation using a Clevenger-type apparatus and the composition of the essential oil was analyzed by gas chromatography-mass spectrometry (GC-MS).

Results: It was found that major constituents of oil were trans-caryophyllene $(8.55 \%)$, isomenthol $(2.98 \%)$, tetrahydrolinalyl acetate $(2.96 \%)$, and pinene $(2.24 \%)$. In other part of the research, the biological activities of superoxide dismutase (SOD) and catalase (CAT) were assayed by in extracts of the leaves spectrophotometric method. It was found the extract contained a considerable superoxide anion radical scavenging power. On the other hand, the biological activity of CAT in extract of COM leaves showed gradual increase during time with a gentle slope indicating an increase in oxidative stress.

Conclusions: The result of our study on Calamintha revealed the existence of a specific component of the essential oil (trans-caryophyllene) that has not been reported by other researchers. In addition to the antioxidant property that was confirmed in this study, the major component of its essential oil was found to be an antimicrobial agent.

Keywords: Calamintha officinalis, Enzymatic Antioxidants, Essential Oil

Citation: Shams Moattar F, Sariri R, Giahi M, Yaghmaee P. Essential oil composition and antioxidant activity of Calamintha officinalis Moench. J Appl Biotechnol Rep. 2018;5(2):55-58. doi:10.29252/jabr.05.02.03.
\end{abstract}

\section{Introduction}

The essential oils are aromatic compounds usually used in medical, food and cosmetic industries. They contain more than 200 diverse compounds, mostly made of monoterpene and Sesquiterpenes hydrocarbons and some branched chemicals such as esters, alcohols, aliphatic aldehydes and ketones. Essential oils are normally produced in fragrant herbs. ${ }^{1}$ Eos have antioxidant and microbicide properties. ${ }^{2,3}$ The herbs from Calamintha sp. are used to add pleasant flavor to the food, due to their characteristic tastes. They are also used in a number of therapeutic applications having anticough and antipyretic properties. ${ }^{4}$

Calamintha officinalis Moench (COM) from Lamiaceae family is very similar to the common mints not only in its appearance but also in terms of its aroma. It is, therefore, commonly used as an alternative to mint for usage in different drinks. ${ }^{5}$ The antioxidant activity of plant extracts and essential oils is of special importance owing to their positive physiological activities on human cells and their potential ability to substitute synthetic antioxidants. ${ }^{6}$

Its essential oil is used in baking as flavoring agent and to add a desirable taste to some pharmacological. It is also consumed for its spicing, sudorific and microbicide effects. ${ }^{7}$

In recent years, numerous researchers have investigated the chemical components in the essential oil of Calamintha species from diverse sources. The purpose of the present study was to obtain the main components of COM plant collected from north area of Iran (Gilan, Lahijan). This was then compared to essential oil composition of COM from other origins. On the other hand, we also aimed to assess the enzymatic antioxidant activity in extracts obtained from the plant's leaves.

\section{Material and Methods \\ Plant Samples}

The plant, COM was collected from northern Iran (Guilan, Lahijan). The fresh leaves were washed with water thoroughly and dried at $40^{\circ} \mathrm{C}$. The leaves were then crushed into small

Copyright (C) 2018 The Author(s). This is an open-access article distributed under the terms of the Creative Commons Attribution License (http:// creativecommons.org/licenses/by/4.0), which permits unrestricted use, distribution, and reproduction in any medium, provided the original work is properly cited. 
pieces and kept frozen for later experiments.

\section{Preparation of Plant Extract}

Frozen leaves (1 $\mathrm{g}$ of fresh mass) were ground in liquid nitrogen and extracted with a cool extraction buffer $3 \mathrm{~mL}$ (50 $\mathrm{mM}$ potassium phosphate, $\mathrm{pH}$ 7.5). The extract was centrifuged for $30 \mathrm{~min}$ at $12000 \mathrm{rpm}$ at $4^{\circ} \mathrm{Cand}$ the resulting supernatants was used as crude extract. ${ }^{8}$

\section{DPPH Free Radical-Scavenging Activity}

DPPH Free radical scavenging activity was estimated by determining the scavenging activity of the essential oil by Burcul with some modification. ${ }^{9}$

\section{Superoxide Radical Scavenging Activity}

One hundred microliters of the plant extract was added to 3 $\mathrm{mL}$ of a reaction mixture and mixed thoroughly. The reaction mixture contained $50 \mathrm{mM}$ potassium phosphate buffer $(\mathrm{pH}$ 7.8), $13 \mathrm{mM}$ methionine, $2 \mu \mathrm{M}$ riboflavin, $0.1 \mathrm{mM}$ EDTA and $75 \mu \mathrm{M}$ NBT. A blank was made of the reaction mixture without enzyme and NBT and the control contained reaction mixture without enzyme. The tubes containing solutions were subjected to $400 \mathrm{~W}$ bulbs $(4 \times 100 \mathrm{~W}$ bulbs) for 15 minutes and the absorbance was read instantly at $560 \mathrm{~nm}^{10}$

The percent scavenging of the superoxide radical was calculated using the following equation:

$\%$ scavenging $=\left(1-\mathrm{A}_{\mathrm{e}} / \mathrm{A}_{0}\right) \times 100$

Where, $A_{0}$ is the absorbance without sample and $A e$ is absorbance with sample. ${ }^{11}$

\section{Catalase Assay}

The catalase $(\mathrm{CAT})$ reaction mixture $(3 \mathrm{~mL})$ contained 50 $\mathrm{mM}$ phosphate buffer ( $\mathrm{pH} 7.0), 15 \mathrm{mM} \mathrm{H}_{2} \mathrm{O}_{2}$ and $0.1 \mathrm{ml}$ of the plant extract. Reaction started as soon as the extract was added to the reaction mixture. Alterations in absorbance of the reaction mixture at $240 \mathrm{~nm}$ were then recorded every 20 seconds. One unit of CAT activity was defined as an absorbance change of 0.01 unit. $\mathrm{min}^{-1}{ }^{12}$

\section{Preparation of Essential Oil}

Dried leaves of the plant (50 g) were hydrodistilled for 3 hours, by a Clevenger-type apparatus. The yield of essential oil was $1 \%(w / w)$. The essential oil was poured out, dehydrated using anhydrous sodium sulfate and stored at low temperature. ${ }^{13}$

\section{Isolation and Analysis of Essential Oil by GC-MS:}

Gas chromatography-mass spectrometry (GC-MS) analysis was performed by Hewlett-Packard (HP-6890), with a crosslinked 5\% phenyl dimethyl siloxane HP-5MS capillary column (dimensions, $30 \mathrm{~m} \times 0.25 \mathrm{~mm}$ ), the carrier gas was helium with a flow rate of $1 \mathrm{~mL} / \mathrm{min}$. The column temperature was set from $60^{\circ} \mathrm{C}$ to $250^{\circ} \mathrm{C}$ at a rate of $6^{\circ} \mathrm{C} / \mathrm{min}$ and the injector and detector (FID) temperature at $250^{\circ} \mathrm{C}$. The injected volume was $0.1 \mu \mathrm{L}$ of the oil with split ratio of $1 / 30$ with an ionizing voltage of $70 \mathrm{eV}$.

The percentage of the essential oil composition was determined by retention indices. Retention indices were defined by retention time for $n$-alkanes that were injected after the essential oil in the same chromatographic conditions. The components were identified by comparing with retention indices found in literature and through comparison of their mass spectra with issued mass spectra data. ${ }^{14}$ Kovats retention indices (KI) were then calculated using the following formula:

$\left.\mathrm{Ix}=100 \mathrm{n}+100\left[\log \left(\mathrm{t}_{\mathrm{x}}^{\prime}\right)-\log \left(\mathrm{t}_{\mathrm{n}}^{\prime}\right)\right] / \log \left(\mathrm{t}_{\mathrm{n}+1}^{\prime}\right)-\log \left(\mathrm{t}_{\mathrm{n}}^{\prime}\right)\right]$

Where $t_{n}^{\prime}$ and $t_{n+1}^{\prime}$ are retention times of the reference n-alkane hydrocarbons eluting instantly before and after compound " $\mathrm{X}$," and $\mathrm{t}_{\mathrm{x}}^{\prime}$ is the retention time of compound "X.". ${ }^{15}$

\section{Statistical Analysis}

Each experiment was repeated at least three times and the statistical analysis were performed using SPSS version 22 statistical software.

\section{Ethical Considerations}

No human or animal samples were used in this study.

\section{Results}

Superoxide Radical Scavenging Activity

Superoxide anions produce active free radicals that can react with biological macromolecules causing tissue injury. Rapid detection of superoxide is highly important, as the lipid peroxidation begins quite instantly. The superoxide anion has a key role in the creation of other free radicals including hydrogen peroxide, hydroxyl radical, and singlet oxygen, which cause oxidative injury in lipids, proteins, and DNA. ${ }^{16}$ Using the following relationship, the activity of COM extract to scavenge superoxide anion was found to be $89.8 \%$. The results obtained from this part of research indicated the high scavenging activity of the $\mathrm{COM}$ extract.

$\%$ scavenging $=\left(1-\mathrm{A}_{\mathrm{e}} / \mathrm{A}_{0}\right) \times 100$

Catalase Assay

CAT converts $\mathrm{H}_{2} \mathrm{O}_{2}$ to nontoxic compounds water and oxygen and, therefore, arise in CAT activity could have a role in the defense of the plants against destroying effect of $\mathrm{H}_{2} \mathrm{O}_{2}$. Specific catalase activity of COM extract was found to be 97 $\mathrm{U} / \mathrm{min} / \mathrm{mg}$ protein. In this study, the activity of CAT showed a significant increase during time (Figure 1).

\section{Identification of Essential Oil Components}

The yield of the essential oil obtained from the leaves of COM extracted by hydro-distillation was $1.0 \%(w / w)$. Identification of the essential oil components were done by GC-MS. Figure 2 is the chromatogram of essential oil from C. officinalis. Fortyone components were isolated, constituting $23.09 \%$ of the total oil. However, only 11 components of the oil were identified in our laboratory (Table 1). The major constituents of this oil were trans-caryophyllene (8.55\%), isomenthol (2.98\%), tetrahydrolinalyl acetate $(2.96 \%)$, and pinene $(2.24 \%)$.

\section{Discussion}

In this paper, CAT and superoxide anion radical scavenging activity of COM extract along with GC-MS analysis of its 


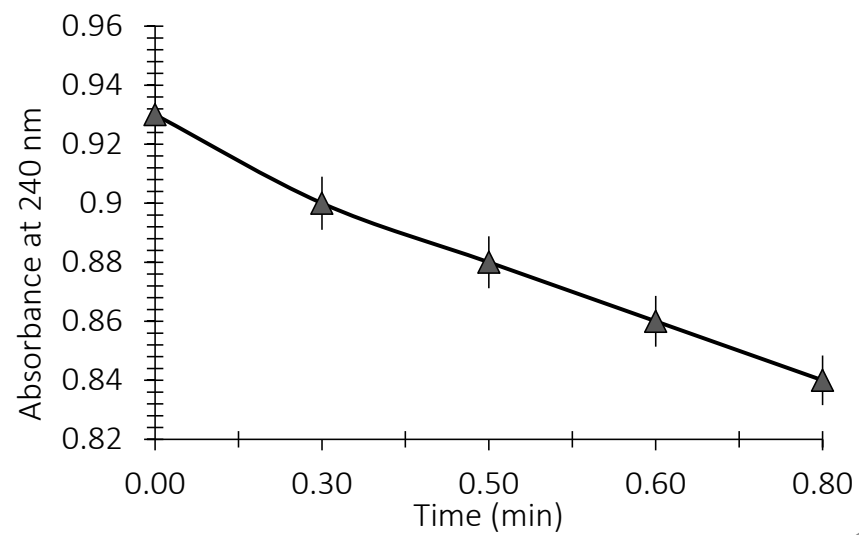

Figure 1. Change in Absorbance of CAT During Time.

essential oil were evaluated. According to our literature survey, it has been reported that although C. officinalis yields comparatively high volume of essential oil with a number of useful pharmacological active compounds, some of them are not still explored pharmacologically. It has also been reported that, similar to other members of mint family, the essential oil of C. officinalis preferably used in baking industry as a flavoring agent. The essential oil also improves the taste and aroma of some medicinal products. It is also usually used for its spicing, sudorific, and microbicide effects.?

The ecological variants, such as temperature, relative moisture, and sun shine period, have an absolute effect on the leaves of COM.?

According to GC-MS results, the major component of the C. officinalis oil was trans-caryophyllene (8.55\%), a bicyclic sesquiterpene, known for anti-inflammatory property. ${ }^{17}$ It has been reported that trans-caryophyllene possess many pharmacological effects including strong antimicrobial property $^{18}$ and ataractic activity. ${ }^{19}$

Bouchra et al reported 1, 8-cineole (36.6\%), pulegone $(17.9 \%)$ and limonene $(9.2 \%)$ as major constituents. ${ }^{20}$ In agreement with our results, a number of compounds have been identified and reported in C. officinalis oil. ${ }^{21}$ However, the major constituents of their oil were carvone

Table 1. Main Components Identified in the Essential Oil of COM

\begin{tabular}{llll}
\hline Name of Component & KI & RT & $\mathbf{( \% )}$ \\
\hline Alpha pinene & 0.939 & 11.62 & 2.24 \\
Cymene<para & 1025 & 13.32 & 0.46 \\
Ocimene< (z)-beta-> & 1037 & 13.49 & 0.53 \\
\hline Acetophenone & 1065 & 14.40 & 0.29 \\
Menthol<iso & 1183 & 17.24 & 2.98 \\
\hline Trans-caryophyllene & 1206 & 17.51 & 8.55 \\
\hline Benzofuran<293-dimethyl-> & 1222 & 17.76 & 1.83 \\
\hline Linalyl acetate<tetra hydro-> & 1234 & 18.07 & 2.96 \\
\hline Pinandiol & 1320 & 19.72 & 1.04 \\
\hline Tetradecan<n-> & 1400 & 21.74 & 0.38 \\
\hline Benzofuran<293-dimethyl-> & 1222 & 17.76 & 1.83 \\
\hline
\end{tabular}

Abbreviations: KI: kovats retention indices, RT: retention time.

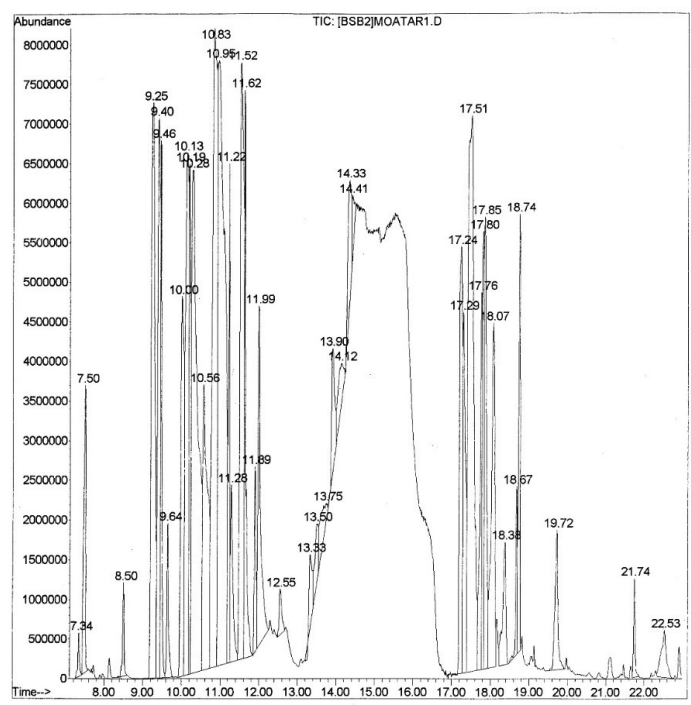

Figure 2. Chromatogram of Calamintha officinalis essential oil.

(46.7\%) and pulegone (22.1\%). Burzo et al from Romani reported p-menthone (28.29), pulegone (48.75) as the main components. ${ }^{4}$

Researchers in Iran have identified thirty-four components in the oil of $C$. officinalis. The major constituents of their oil were $\beta$-bisabolene (9.9\%), germacrene D (7.6\%), $\beta$-bourbonene $(7.4 \%)$ and piperitenone $(5.3 \%){ }^{22}$

A report from Egypt has shown a number of various compounds including carvone $(38.7 \%)$, neo-dihydrocarveol (9.9\%), dihydrocarveol acetate (7.6\%), dihydrocarveol (6.9\%), 1,8 cineole $(6.4 \%)$, cis-carvyl acetate $(6.1 \%)$, and pulegone (4.1\%) as the major components of their essential oil. ${ }^{7}$

The result of our study on Calamintha revealed the existence of a specific component of the essential oil (trans-caryophyllene) that has not been reported by other researchers. It has been reported that trans-caryophyllene possesses strong antimicrobial property. ${ }^{18}$ It is expected, therefore, that our essential oil should exhibit antibacterial activity. This is the remaining part of research that should be explored and reported later. However, antimicrobial property of C. officinalis essential oil has been reported by other researchers. $^{23}$

The free radical scavenging activity of essential oil was determined by DPPH method. The results have indicated that these essential oil possess a low inhibitory activity (21\%) relative to plant extract.

We also measured CAT and SOD activities in COM extract, a line of research that has not been reported for this plant in the literature.

CAT is a major antioxidant defense enzyme that primarily catalyses the decomposition of $\mathrm{H}_{2} \mathrm{O}_{2}$ to $\mathrm{H}_{2} \mathrm{O}$ and $\mathrm{O}_{2}$. The CAT activity of COM extract was significantly increased during time.

Oxygen derived free radicals, such as the superoxide anion and hydroxyl radical are cytotoxic and promote tissue injury. Antioxidants act as a major defense against radical mediated toxicity by protecting from the damages caused by free radicals. Furthermore, although medicinal plants are 
used as 'antioxidants' in traditional medicine, their claimed therapeutic properties could be due, in part, to their capacity for scavenging oxygen free radicals. ${ }^{17}$ We found that the free radical scavenging activity of the COM extract was quite considerable.

Results of our experiment confirmed that COM extract can protect human cells against oxidative damage due to the activity of these enzymes, and it is suggested that strong antioxidant properties of COM can be used for therapeutic or pharmaceutical applications in future.

In this study, the essential oils of $C$. officinalis were extracted by hydrodistillation. It was observed that the plant contains large amount of essential oil and only 11 components of the oil were identified in our research. Trans-caryophyllene (8.55\%) was the main constituent of this oil. The compound is known for its anti-inflammatory and antimicrobial properties. In addition to the antioxidant property that was confirmed in this study, the major component of its essential oil was found to be an antimicrobial agent. It was, therefore, concluded that based on the results of this study, the essential oil of COM from northern Iran could be considered as a reasonable candidate for food and pharmaceutical industries.

\section{Conclusions}

The result of our study on Calamintha revealed the existence of a specific component of the essential oil (trans-caryophyllene) that has not been reported by other researchers. Results of our experiment confirmed that COM extract can protect human cells against oxidative damage due to the activity of these enzymes, and it is suggested that strong antioxidant properties of COM can be used for therapeutic or pharmaceutical applications in future.

\section{Authors' Contributions}

All authors equally contributed to the present study.

\section{Conflict of Interest Disclosures}

The authors declare they have no conflicts of interest.

\section{Acknowledgements}

This study was supported by Islamic Azad University, Lahijan, Iran and Guilan University, Rasht, Iran.

\section{References}

1. Kamaliroosta L, Zolfaghari M, Shafiee S, Larijani K, Zojaji M. Chemical Identifications of Citrus Peels Essential Oils. J Food Biosci Technol. 2016;6(2):69-76.

2. Bozovic M, Garzoli S, Sabatino M, et al. Essential Oil Extraction, Chemical Analysis and Anti-Candida Activity of Calamintha nepeta (L.) Savi subsp. glandulosa (Req.) Ball-New Approaches. Molecules. 2017;22(2). doi:10.3390/molecules22020203.

3. Pellegrini M, Ricci A, Serio A, et al. Characterization of Essential Oils Obtained from Abruzzo Autochthonous Plants: Antioxidant and Antimicrobial Activities Assessment for Food Application. Foods. 2018;7(2). doi:10.3390/foods7020019.

4. Burzo I, Mihaescu D, Dobrescu A, Ambarus S, Falticeanu M, Badulescu L. Contribution to the knowledge of the composition of the essential oils from five Calamintha species cultivated in Romania. Scientific Annals of Alexandru loan Cuza University of lasi New Series, Section 2 Vegetal Biology. 2006;52:39-42.

5. Verma M, Irchhaiya R, Singh P, Kailasiya D, Kanaujia V. Studies on antiulcer activity of essential oil of Calamintha officinalis moench.
Int J Pharm Sci Res. 2011;2(10):2733-2736. doi:10.13040/IJPSR.

6. Ruiz-Ciau D, Cuevas-Glory L, Quijano L, Sauri-Duch E. Chemical Composition and Antioxidant DPPH Activity of the Floral and Leaves Essential Oils of cMontanoa speciosa DC. Am J Plant Sci. 2017;8(4):745-753. doi:10.4236/ajps.2017.84052.

7. Monforte MT, Tzakou O, Nostro A, Zimbalatti V, Galati EM. Chemical composition and biological activities of Calamintha officinalis Moench essential oil. J Med Food. 2011;14(3):297-303. doi:10.1089/jmf.2009.0191.

8. Salekjalali M, Haddad R, Jafari B. Effects of soil water shortages on the activity of antioxidant enzymes and the contents of chlorophylls and proteins in barley. Am Eur J Agric Environ Sci. 2012;12(1):57-63.

9. Burcul F, Generalic Mekinic I, Radan M, Rollin P, Blazevic I. Isothiocyanates: cholinesterase inhibiting, antioxidant, and antiinflammatory activity. J Enzyme Inhib Med Chem. 2018;33(1):577582. doi:10.1080/14756366.2018.1442832.

10. Siavoshi M, Laware SL. Organic Fertilizers Role on Antioxidant Enzymes in Rice (Oryza sativa L.). International Journal of Farming and Allied Sciences. 2013;2(S2):1337-1342.

11. Meenu Krishnan VG, Murugan K. Antioxidant potentiality of partially purified protease inhibitor from the fruits of African nightshade (Solanum aculeatissimum Jacq.). World J Pharm Pharm Sci. 2013;2(6):5166-5181.

12. Rached-Kanouni M, Alatou D. Change in activity of antioxidative enzymes in leaves of Acacia retinodes, Biota orientalis and Casuarina equisetifolia under heat stress condition. Eur Sci J. 2013;9(24):402-410. doi:10.19044/esj.

13. Pavlovic M, Kovacevic N, Tzakou O, Couladis M. Essential oil composition of Sanicula europaea L. Flavour Fragr J. 2006;21(4):687-689. doi:10.1002/ffj.1672.

14. Rastakhiz N, Azar PA, Tehrani MS, Moradalizadeh M, Larijani K. Comparison of the chemical components of essential oil extracted by MAHD and SPME methods from two species of Salvia from Iran. Int J Life Sci. 2015;9(2):61-64. doi:10.3126/ijls.v9i2.12051.

15. Babushok VI, Linstrom PJ, Zenkevich IG. Retention indices for frequently reported compounds of plant essential oils. J Phys Chem Ref Data. 2011;40(4):043101-43147. doi:10.1063/1.3653552.

16. Hasnat A, Pervin M, Lim BO. Acetylcholinesterase inhibition and in vitro and in vivo antioxidant activities of Ganoderma lucidum grown on germinated brown rice. Molecules. 2013;18(6):66636678. doi:10.3390/molecules18066663.

17. Jainu M, Devi CSS. In Vitro. and In Vivo. Evaluation of Free-Radical Scavenging Potential of Cissus quadrangularis. Pharm Biol. 2005;43(9):773-779. doi:10.1080/13880200500406636.

18. Astani A, Reichling J, Schnitzler P. Screening for antiviral activities of isolated compounds from essential oils. Evid Based Complement Alternat Med. 2011;2011:253643. doi:10.1093/ecam/nep187.

19. Chavan MJ, Wakte PS, Shinde DB. Analgesic and anti-inflammatory activity of Caryophyllene oxide from Annona squamosa L. bark. Phytomedicine. 2010;17(2):149-151. doi:10.1016/j. phymed.2009.05.016.

20. Bouchra C, Achouri M, Idrissi Hassani LM, Hmamouchi M. Chemical composition and antifungal activity of essential oils of seven Moroccan Labiatae against Botrytis cinerea Pers: Fr. J Ethnopharmacol. 2003;89(1):165-169. doi:10.1016/s03788741(03)00275-7.

21. Nickavar B, Mojab F. Hydrodistilled Volatile Constituents of Calamintha officinalis Moench from Iran. Journal of Essential Oil Bearing Plants. 2005;8(1):23-27. doi:10.1080/097206 0X.2005.10643416.

22. Morteza-Semnani K, Akbarzadeh M. The Essential Oil Composition of Calamintha officinalis Moench from Iran. Journal of Essential Oil Bearing Plants. 2007;10(6):494-498. doi:10.1080/097206 0X.2007.10643585.

23. Nostro A, Cannatelli MA, Morelli I, et al. Efficiency of Calamintha officinalis essential oil as preservative in two topical product types. J Appl Microbiol. 2004;97(2):395-401. doi:10.1111/j.13652672.2004.02319.x. 